\title{
Treatment of Furcation Lesions in Devital Teeth with B-Tricalcium Phosphate + Hydroxyapatite Graft Material: A Case Report
}

\author{
Bozan Serhat İzol ${ }^{1}$, Arzum Güler Doğru², Fikret İpek², Ahmet Günay² \\ ${ }^{1}$ Research Assistant, Dicle University, Faculty of Dentistry, Department of Periodontology, Diyarbakır, TURKEY. \\ ${ }^{2}$ Assistant Professor, Dicle University, Faculty of Dentistry, Department of Periodontology, Diyarbakır, TURKEY.
}

\section{Key Words}

Furcation lesion, B-Tricalcium Phosphate, hydroxyapatite graft

\section{Correspondence:}

Arzum Güler DOĞRU

Dicle University, Faculty of Dentistry, Department of Periodontology, Diyarbakır, TURKEY.

e-mail: agdogru@yahoo.com

\begin{abstract}
Endoperiodontal lesions are characterized by the presence of periodontal and pulpal disease within the same dental element. Periodontal and pulpal tissues are related to each other by lateral and accessory canals, the apical foramen, and the dentinal tubules. In the dental literature, whether periodontal disease affects pulpal disease or vice versa remains controversial. Pulpal disease is often accepted to cause periodontal disease. The treatment of endodonticperiodontal combined lesions requires both endodontic therapy and periodontal regenerative procedures. The success rate of treatment comprising only an endodontic procedure for such lesions is low. Periodontal regenerative therapy has been used widely to regenerate periodontium lost due to periodontal disease. This therapy is also very successful during the management of endodontic-periodontal lesions.
\end{abstract}

(Int Dent Res 2012;2(3):81-85)

\section{Introduction}

One of the main objectives of periodontal treatment, including the addition of new bone, cementum and periodontal ligament regeneration, involves ensuring the security of new attachments. Due to the complex anatomy of the furcation areas associated with multi-rooted teeth, the resulting loss of attachment area has been of intense interest for periodontists $(1,2)$.

A tooth with both periodontal and endodontic disease is defined as having endoperiodontal lesions. Pulpal and periodontal tissues are examined at the same time as the source of these lesions, including primary endodontic, periodontal, and combination primary lesions, and are classified into three groups (3).

Dental pulp tissue is the primary carrier of coronal leakage and infection due to trauma-related injuries $(4,5)$. If left untreated, infected pulp tissue affects the periapical region. The regions formed in these reactions are usually seen in the apex of the tooth (4). However, the root opening on the side of accessory canals in furcation areas or in multi-rooted teeth can create a periodontal pathology (6).

Anaerobic infections are common in the etiology of periodontal diseases (7). Similarly, necrotic pulp tissue in endodontic diseases is known to be affected by anaerobic infection. The similarity between the endodontic and periodontal microflora in the root canal of the periodontal pocket suggests 
occurrence of cross-infection. This idea is supported by the finding that the pulp and the periodontal ligament between the anatomical pathways (8). The main portion of pulp and periodontal tissue is located at the apical foramen. In addition, accessory canals and dentinal tubules represent potential physiological pathways allowing the passage of bacteria and their products (9); however, since other structures create a barrier against penetration of bacteria, such as physiological dentin and cementum, dentin tubule-infected pulp tissue is very unlikely to become infected through the periodontium (9).

Teeth with periapical pathology with a negative prognosis affect the amount of marginal bone loss $(10,11)$. The guided tissue regeneration (GTR) technique, in areas difficult to treat by conventional methods, is an alternative for the treatment of these combined lesions. A limited number of cases in the literature have reported positive results (12-21). The purpose of this research was regeneration of primary teeth, using periodontal treatment and endodontic endo-perio-problematic clinical and radiographic methods to evaluate the effectiveness.

\section{Case Report}

A patient complaining of pain and bleeding of the gums in the left lower region of the mouth was admitted to our clinic. Intraoral and radiographic examination revealed that the left lower molar showed deep furcation. A periodontal pocket depth of $10 \mathrm{~mm}$ was observed (Fig. 1a-1b).

To eliminate tooth mobility, a splint was created with adjacent teeth. For the treatment of the root canal, the patient was redirected to an endodontic clinic. Endodontic treatment started with initial periodontal treatment. After the initial periodontal and endodontic therapy for the treatment of furcation lesions the patient decided to continue regenerative periodontal surgery. Under local anesthetic, a full-thickness flap, including granulation tissue in the furcation, was removed and the root surface was flattened. The region was then filled with B-tricalciumphosphate + hydroxyapatite graft material and sutured (Figure $2 a-2 b$ ). Twelve months after inspection, complete remission of the region was observed (Fig. 3a-3b).
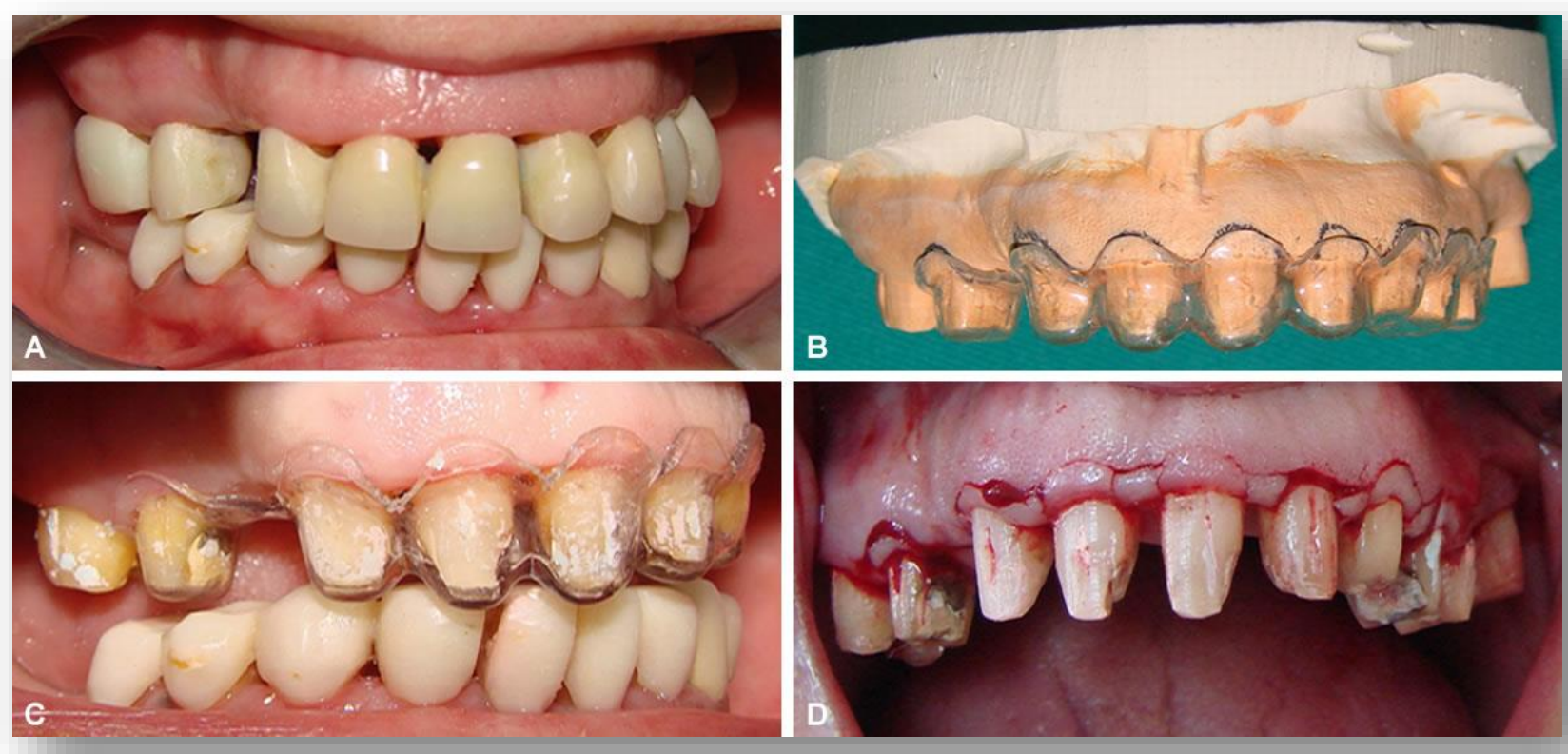

Figure 1. (A) The patient presented with unsatisfactory aesthetics in the anterior gingiva and prosthesis; (B) The surgical guide was constructed of thermoforming material; (C) The seating of the surgical guide in the patient's mouth was evaluated; (D) Vertical mini-incisions were made on the mesial and distal sides of each papilla. 

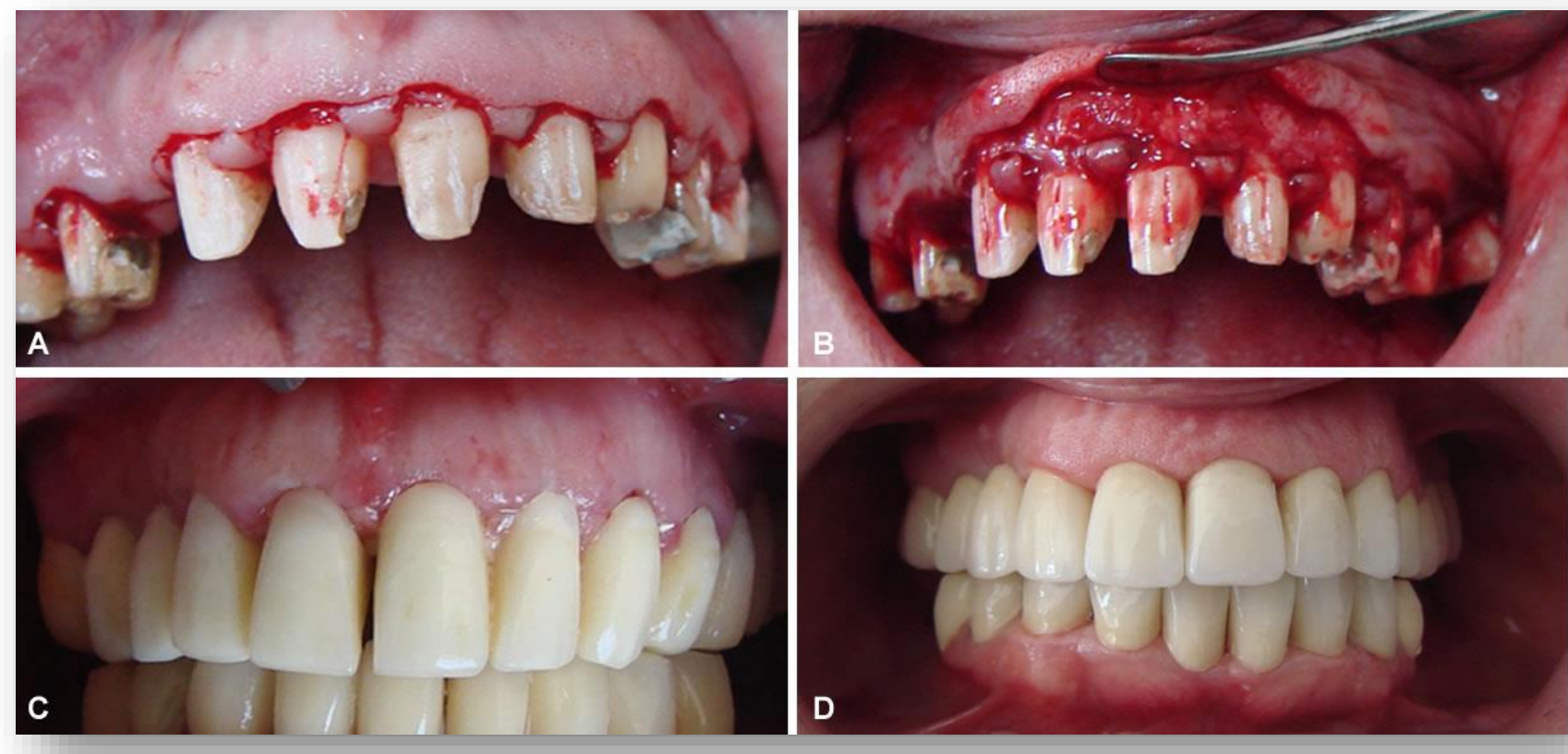

Figure 2. (A) The gingiva on the labial aspects of all teeth was removed; (B) A full-thickness labial flap was reflected; (C) The patient's condition 1 week postoperatively; (D) Final restoration.

\section{Discussion}

The rate of healing following non-surgical endodontic treatment of teeth with periapical lesions has been reported to be $73-90 \%(22,23)$. Real apical cysts have a reported success rate of $73.8 \%$ in teeth with large lesions. For the treatment of endo-perio lesions other than root fracture combined with endodontic treatment initiation a follow-up clinical course of at least 3 months is proposed (21) Therefore, the combined endodontic lesions will improve with conventional endodontic treatment, it has been suggested (24) scientific evidence supporting this view is quite low (25). Long-term follow-up of $35-60 \%$ of patients after endodontic treatment is possible $(22,23)$. It is not possible to predict the outcome of treatment in patients without a follow-up being performed.

Periapical pathology in patients with periodontal destruction caused over time by periodontal pocket epithelial tissue, reduces the chances of successful endodontic treatment (26). Advanced stages of periapical pathology observed in cases of marginal periodontal destruction, bone grafts, and GTR resulted in a $27-37 \%$ chance of successful endodontic surgery $(10,11)$. The application of regenerative periodontal surgery to endodontic therapy resulted in a success rate of $80 \%$, consistent with the report by Dietrich et al., who reported $83 \%$ success. These findings suggest that endodontic surgery may increase the success rate, a view supported by other authors (25).

A significant decrease in cell depth was identified in the current study. The pocket depth reduction over 12 months suggests that the surgical technique was effective. Dietrich et al., discuss similar cases; a significant decrease in pocket depth was obtained using regenerative periodontal therapy (25).

Radiographic evaluation of the success of endodontic therapy reveals significant findings. However, studies using bone grafts suggest that radiopaque radiographic findings should be interpreted cautiously. Reports in the literature are inconsistent with regards to the methods used and the duration of graft resorption (27-32). Radiographic examination can identify normal bone graft in the early postoperative period; however, radiopacity may become more intense over time. A 1-year follow-up period may be adequate for the assessment of graft material used in the cases reported (33).

In actual combined endo-perio lesions, the periapical lesion is accompanied by necrotic pulp and marginal periodontitis. These lesions can 
develop independently, such that one might be the precursor of another.

The primary endodontic lesion in this case report suggests the overall periodontal health of the patient to be good. Conflicting opinions exist regarding the use of antibiotics during routine endodontic surgical procedures (33). In our study, the use of antibiotics was important due to bone graft application. For this reason, we adminstered oral penicillin, which is frequently used in surgical procedures (34). Local antibiotics have been reported to have a negative impact on the effectiveness of the bone grafts and thus antibiotics were administered orally (35).

\section{Acknowledgments}

The authors deny any conflicts of interest related to this study.

\section{References}

1. Chase R Sr, Low SB. Survival characteristics of periodontally involved teeth: A 40 year study. J Periodontol. 1993;64:701-706.

2. Ross IF \& Thompson RH Jr. A long term study of root retention in the treatment of maxillary molars with furcation involvement. J Peirodontol.1978;49:238-242.

3. Simon JHS, Glick DH, \& Frank AL. The relationship of endodontic-periodontic lesions. J Periodontol. 1972;43:202- 208.

4. Reeves R \& Stanley HR. The relationship of bacterial penetration and pulpal pathosis in carious teeth. Oral Surg Oral Med Oral Pathol. 1966;22:59-65.

5. Madison S \& Wilcox LR. An evaluation of coronal microleakage in endodontically treated teeth. Part III. In vivo study. J Endod. 1988;14:455-458.

6. Simring $M \&$ Goldberg $M$. The pulpal pocket approach: Retrograde periodontitis. J Periodontol. 1964;35:22-48.

7. Loesche WJ. The antimicrobial treatment of periodontal disease: Changing the treatment paradigm. Critical Reviews in Oral Biology and Medicine. 1999;10:245-275.

8. Kerekes $\mathrm{K}$ \& Olsen I. Similarities in the microfloras of root canals and deep periodontal pockets. Endod Dent Traumatol. 1990;6:1-5.

9. Zehnder M, Gold SI, \& Hasselgren G. Pathologic interactions in pulpal and periodontal tissue. J Clin Periodontol. 2002;29:663-671.
10. Hirsch JM, Ahlstrom U, Henrikson PA, Heyden G, \& Peterson LE. Periapical surgery. Int J Oral Surg. 1979;8:173-85.

11. Skoglund A \& Persson G. A follow-up study of apicoectomized teeth with total loss of the buccal bone plate. Oral Surg Oral Med Oral Pathol. 1985;59:78-81.

12. Zubery $Y$ \& Kozlovsky A. Two approaches to the treatment of true combined periodontalendodontal lesions. J Endod. 1993;19:414-6.

13. Abramowitz PN, Rankow $\mathrm{H}$, \& Trope $M$. Multidisciplinary approach to apical surgery in conjunction with the loss of buccal cortical plate. Oral Surg Oral Med Oral Pathol. 1994;77:502-6.

14. Cortellini P, Pini Prato G, \& Tonetti MS. The modified papilla preservation technique with bioresorbable barrier membranes in the treatment of intrabony defects. Int J Periodontics Restorative Dent. 1996;16:546-59.

15. Kellert M, Chalfin $H$, \& Solomon C. Guided tissue regeneration: an adjunct to endodontic surgery. J Am Dent Assoc. 1994;125:1229-33.

16. Rankow HJ \& Krasner PR. Endodontic applications of guided tissue regeneration in endodontic surgery. J Endod. 1996;22:34-43.

17. Tseng CC, Harn WM, Chen YH, Huang CC, Yuan $\mathrm{K}$, \& Huang PH. A new approach to the treatment of true combined endodontic-periodontic lesions by the guided tissue regeneration technique. J Endod. 1996;22:693-6.

18. Uchin RA. Use of a bioresorbable guided tissue membrane as an adjunct to bony regeneration in cases requiring endodontic surgical intervention. J Endod. 1996;22:94-6.

19. Milano F \& Melsen B. Guided tissue regeneration using bioresorbable membranes: what is the limit in the treatment of combined periapical and marginal lesions? Int J Periodontics Restorative Dent. 1997; 17:416-25.

20. Pompa DG. Guided tissue repair of complete buccal dehiscences associated with periapical defects: a clinical retrospective study. J Am Dent Assoc. 1997; 128:989-97.

21. Brugnami F \& Mellonig JT. Treatment of a large periapical lesion with loss of labial cortical plate using GTR: a case report. Int J Periodontics Restorative Dent. 1999;19:243-9.

22. Friedman S, Abitbol $S, \&$ Lawrence HP. Treatment outcome in endodontics: the Toronto Study. Phase 1: initial treatment. J Endod. 2003;29:787-93.

23. Friedman $S$, Abitbol $S$, \& Lawrence HP. Treatment outcome in endodontics: the Toronto Study. Phase 1: initial treatment. J Endod. 2003;29:787-93.

24. Meng HX. Periodontic-endodontic lesions. Ann Periodontol. 1999;4:84-90.

25. Dietrich $T$, Zunker $P$, Dietrich $D, \&$ Bernimoulin JP. Periapical and periodontal healing after osseous grafting and guided tissue regeneration treatment of apicomarginal defects in 
periradicular surgery: Results after 12 months. Oral Surg Oral Med Oral Pathol Oral Radiol Endod. 2003;95:474-82.

26. Haueisen $H$ \& Heidemann D. Hemisection for treatment of an advanced endodontic-periodontal lesion: a case report. Int Endod J. 2002;35:55772.

27. Artzi $Z$, Tal H, \& Dayan D. Porous bovine bone mineral in healing of human extraction sockets. Part I: histomorphometric evaluations at 9 months. J Periodontol. 2000;71:1015-23.

28. Arau'jo MG, Carmagnola $D$, Berglundh $T$, Thilander B, \& LindheJ. Orthodontic movement in bone defects augmented with Bio-Oss. An experimental study in dogs. J Clin Periodontol. 2001;28:73-80.

29. McAllister BS, Margolin MD, Cogan AG, Buck D, Hollinger JO, \& Lynch SE. Eighteen-month radiographic and histologic evaluation of sinus grafting with inorganic bovine bone in the chimpanzee. Int J Oral Maxillofac Implants. 1999;14:361-8.

30. Terheyden $\mathrm{H}$, Jepsen $\mathrm{S}$, Moller B, Tucker MM, \& Rueger DC. Sinus floor augmentation with simultaneous placement of dental implants using a combination of deproteinized bonexenografts and recombinant human osteogenic protein-1. A histometric study in miniature pigs. Clin Oral Implants Res. 1999;10:510-21.

31. Valentini $P$, Abensur D, Densari D, Graziani JN, \& Hammerle C. Histological evaluation of Bio-Oss in a 2-stage sinus floor elevation and implantation procedure. A human case report. Clin Oral Implants Res. 1998;9:59-64.

32. Young C, Sandstedt $P$, \& Skoglund A. A comparative study of inorganic xenogenic bone and autogenous bone implants for bone regeneration in rabbits. Int J Oral Maxillofac Implant. 1999;14:72-6.

33. Zuolo ML, Ferreira MOF, \& Gutmann JL. Prognosis in periradicular surgery: a clinical prospective study. Int Endod J. 2000;33:91-98.

34. Meister F Jr, Lommel T J, \& Gerstein H. Diagnosis and possible causes of vertical root fractures. Oral Surgery, Oral Medicine and Oral Pathology. 1980;49: 243-253.

35. Peterson $\sqcup$. Principles of management and prevention of odontogenic infections. In: Peterson L, Ellis E, Hupp JR, \& Tucker MR, Contemporary oral and Maxillofacial surgery. 2nd. Ed. St Louis, Mosby. 1993:409-435. 